\title{
Bicultural Resourcefulness in Global Management: From Education to Corporate Collaboration
}

\author{
LISBETH CLAUSEN AND MARIA HVASS KEITA
}

\begin{abstract}
Biculturals are increasingly viewed as a resource in global business. They are effective in multicultural teams, they are great boundary spanners between corporate headquarters and their subsidiaries, and their abilities are acknowledged in cross-cultural leadership. This article aims to generate typologies that will help global businesses gain a clearer understanding of the competences that biculturals can offer them. This study explores biculturalism in two settings: business education and global corporations. What unique skills and abilities allow biculturals to take advantage of knowledge from two or more cultures? Do they perceive their skills as resources? And how does corporate experience harness bicultural competences? Surprisingly, this study showed that the bicultural students were not aware of their strengths and advantages. In contrast, the corporate study provided ample evidence of how bicultural abilities were acknowledged and leveraged in international business, once bilculturals were established in the workplace. This article presents a theoretical matrix of bicultural competences, based on the concepts of frame switching and meta-cognition. The matrix categories are: 1) bicultural dissonance, 2) bicultural thinking, 3) bicultural action and 4) bicultural competence.
\end{abstract}

Keywords: biculturalism, business, competence, frame switching, meta-cognition

\section{Introduction}

This article investigates perceptions of biculturalism as a resource in educational and corporate collaboration settings. ${ }^{1}$ Biculturals are individuals who have internalised two or more cultures. Due to their particular skillsets and acuity gained from exposure and upbringing in two or more cultures they are increasingly found to be resourceful in global business (Brannen and Thomas 2010, Brannen et al. 2009, Brannen 2009). ${ }^{2}$ They are effective in multicultural teams (Hong 2010). They are great boundary spanners between corporate headquarters and their subsidiaries (Furuzawa and Brewster, 2015) and their abilities are 
acknowledged in cross-cultural leadership (Lakshman 2013). However, the resources of bicultural employees still remain to be fully tapped in global business (Fitzsimmons et al 2011). Towards this goal, it will be useful to produce more typologies through which to understand the competences of biculturals (Brannen and Thomas 2010).

The focus of this article is biculturalism in business education and global corporations. What unique skills and abilities allow biculturals to take advantage of knowledge from two or more cultures? Do they perceive their skills as a resource? And how does corporate work experience harness bicultural competences? Using qualitative research methods, we seek to demonstrate how intercultural competences are perceived by 1) students of international business whose upbringing was directly influenced by several cultures (the education study), and 2) employees with considerable working experience in a global business environment (the corporate study).

Our research revealed that the bicultural students in the education study were not aware of their strengths and unique skills, whereas the corporate study showed how bicultural abilities were positively acknowledged and viewed as leverage in international business. Our study presents a theoretical matrix of bicultural competences and resources, which is later used in the two studies.

The article is structured as follows: first, we review the literature on biculturalism as a cross-cultural competency. Second, we introduce our matrix of bicultural competences, based on frame switching and meta-cognition. Third, we describe the context of the two case studies (education and corporate) and the method of data collection. Fourth, we present the analysis of the case studies, based on the matrix of bicultural resources, including a) coping with bicultural dissonance b) bicultural thinking, c) bicultural action, and d) bicultural competence. Finally, we discuss the categories of bicultural competences observed in multinational corporations and assess the theoretical and practical implications of our findings.

\section{Biculturalism as a Cross-cultural Competence}

Global managers inevitably co-operate across national and professional borders. The challenge is to embrace the insecurity, turbulence and change that globalization brings about in leadership and management. This involves moving beyond their comfort zones to conquer new markets and apply new management styles (Bartlett and Goshal 2007). 
Biculturals may provide a solution to the business management challenges created by globalization (Gillespie et al. 2010). A number of multinational corporations have discovered the potential of bi- and multicultural people. Sony Ericsson, for example, employed a bicultural, Hata Hitori, as a CEO to manage its transnational operations. He combined language abilities and cultural insights drawn from both Japan and the USA.

Biculturalism may be defined as the internalization of two or more cultures (Brannen and Thomas 2010) and the multifaceted resources gained through either birth and upbringing or education and experience. Biculturals often have cross-cultural competences and are therefore useful players in global business. Cross-cultural competence is 'the ability to function effectively in another culture' (Gertsen 1990: 346). Cultural competence, more generally, requires management of oneself and of relationships with others. The notion of a 'global mindset' is increasingly advocated in global business, and managers are expected to work towards adaptation and integration across diverse cultures, languages, departments, management styles, markets and consumer preferences at both individual and organizational levels (Gupta and Govindarajan 2002).

Crucially, the most effective managers take time to reflect (Lyndon and Thøgersen 2006). Global executives may distinguish themselves from local leaders precisely because they have the courage to seize new opportunities and experiences. They are better able to overcome 'culture shock' as they are prepared for the potential disorientation in new contexts (Adler 1975, Rhinesmith 1985). One competence relating to the ability to deal with uneasiness in new cultural contexts is the ability to balance paradox, such as dealing with competing or even contradictory cultural values (McCall and Hollenbeck 2002). The ability to limit cultural 'bias' and the propensity to move beyond the familiar ways of one's own (or primary) culture were found to be key components in the development of 'cultural sensitivity' (Shapiro et al. 2008). The highest levels of cultural sensitivity involve a form of reflexivity in which individuals forge transcultural understandings and critically apply these understandings to their own cultural norms (Shapiro et al. 2008:83). In short, cultural intelligence combined with cross-cultural competence enables people to function in different cultural contexts in an appropriate manner (Earley and Ang 2003, Thomas 2006, Thomas et al. 2008). Biculturals often display both these traits. The following section elaborates on the general characteristics of biculturalism, and discusses when and how these may be drawn upon in specific social interactions. 


\section{Bicultural Competences: A Theoretical Framework}

This study is based on certain theoretical assumptions. In The Art of War, the Chinese philosopher Sun Tzu notes that 'one cannot enter into alliances without knowing the design of one's neighbor' (Tzu 2012). In the light of this statement, biculturals are by nature resourceful because, within a single individual, they embody the design of the neighbour within the design of the self.

The competences of bicultural individuals are further affected by their cultural identity. Identity is the sense of self, formed by beliefs, values, attitudes, traditions and ways of life drawn from group membership; identity is subject to change over time and through negotiation in relation to others through life experiences (Jameson 2007). The constant negotiation of two sets of cultural influences in turn contributes to their unique set of competences. Biculturals, as mentioned above, are defined as individuals who have internalized two or more cultures (among others Brannen and Thomas 2010, Hong 2010, Briley et al. 2005). They are individuals who think and act within two or more distinct cultural frames of reference.

Previous research has sometimes emphasised the psychological toll and more negative consequences of existing within two or more cultural contexts (Hong et al. 2000). However, in more recent studies it has become more widely accepted that being exposed to several cultures will elicit negative as well as positive effects on the individual's mental state and ability to interact with others (Hong et al. 2000). There has been a tendency to focus on the long-term effects of biculturalism, i.e. 'the challenges and outcomes associated with long-term adaptation to a foreign culture' (Molinsky 2007: 622). We adhere to the notion that cross-cultural interaction can be considered 'the micro building blocks of long term adjustment to a foreign setting' (Molinsky 2007: 622). While it is important to understand the psychological impact of long-term expatriation, for example, it is also important to explore the micro-processes that help prepare individuals to cope with facing new cultures. Rather than believing that biculturalism is rooted in an essence or a core of competences within an individual, various factors may influence a given interaction. Thus, taking this social constructivist position that biculturalism is constructed through interaction, we are able to understand how different situations may instigate different reactions and emotions. This approach implies a respect for the nature of processes, acknowledging that individuals never exist in a vacuum. 
Experiences are co-produced in continuous interaction and communication with other individuals, who are likely to have equally unique knowledge structures, perceptions and motivations for engaging in the interaction (Stacey 2007).

Brannen and Thomas (2010) propose that internalisation of more than one culture can be attained through either origin or experience. Our position differs slightly; although biological heritage may be the direct cause of biculturalism, biculturalism is always attained through experience. It is through the exposure to and participation in a culture that the cultural frames are enacted. Thus, culture is viewed as a social construction, incessantly produced and reproduced through the individuals who participate in the interaction (Stacey 2007). Knowledge of the values, norms and expected behaviours of a given culture, also termed culture-specific knowledge, is therefore best achieved through interaction within that culture. Linguistic excellence has long been promoted in the international business literature as an advantage and asset in cross-cultural management (Harzing and Feely 2008, Peltokorpi and Clausen 2011, Brannen 2015). We adhere to the position that bicultural competences are often (although not always) linked to fluency in two languages (Ringberg et al. 2010).

\section{Cultural Frame Switching}

The notion of cultural frame is central to our analysis and definition of biculturalism. Cultural frames are the 'rules' that are associated with a particular cultural setting. A considerable amount of research on individuals in bicultural settings has been carried out within the field of psychology (Molinsky 2007, Briley et al. 2005, Hong et al. 2000). A significant portion of this literature focuses on how bicultural individuals cope with and are influenced by what can be termed cultural frame switching (see LaFromboise et al. 1993 for a review; Molinsky 2007, Briley et al. 2005, Hong et al. 2000).

Frame switching allows bicultural individuals to interpret their surroundings and take appropriate actions as they move between contexts that are primarily associated with one culture or another (Briley et al. 2005: 351). Biculturals have internalised a number of cultural frames.

When biculturals switch frames, they are assessing the context in which they find themselves and, based on the cues, they adjust their thought processes accordingly (Hong et al. 2000). Frame switching has been scrutinised in terms of the psychological impact on the individual 
performing the switch, but it has also been investigated in terms of how the switch is prompted. There are basically two opposing positions, namely that frame switching is the cause of experienced triggers of cultural knowledge in the given context, i.e. an automatic response (Hong et al. 2000), or that it is a motivated choice that directs thought and behaviour, i.e. a conscious response (Briley et al. 2005). Both are ways of explaining how it is possible for an individual to change their cultural viewpoint. Hong el al. (2000) presents frame switching as the process of activating accessible domain-specific knowledge structures, an unconscious reaction to stimuli. In that study, the researchers exposed the bicultural subjects to images of distinct cultural artefacts. For instance, when primed with images of Chinese versus American culture (i.e. the Great Wall versus the US Capitol), bicultural individuals from Hong Kong switched their attribution pattern in the direction that was normative in the culture that was activated by these images. The results thus showed that the subjects would change cultural frame accordingly (2000). This dynamic constructivist approach offers an explanation of how it is possible to internalise more than one culture, enabling the subject to bring forth knowledge based on cues in the social setting and context. In other words, culture is not a commanding predisposition in terms of 'an overall mentality, worldview, or value orientation' (Hong et al. 2000: 710). Rather, culture exists latently in a person as 'a loose network of domain[context]-specific knowledge structures; such as categories and implicit theories,' enabling a person to access more or less conscious experience-based knowledge to help them respond appropriately in a given situation (Hong et al. 2000).

The alternative position, which posits that frame switching is a conscious reaction to circumstances, proposes that the action of switching frames is directed by an individual's motivation to conform to internal or external expectations (Briley et al. 2005). This indicates operability, which can be thought of as a tool or resource. For the purpose of this article, this latter position is preferable, although we do not subscribe to the notion that frame switching is always a deliberate action. Rather, we believe that frame switching can be both reactive and deliberate. We argue that it is when the switch is performed from an informed position that it becomes resourceful. An 'informed position' assumes reflexivity and awareness or 'mindfulness' (Thomas 2006) of the situations an individual finds themselves in, as will be discussed below. 


\section{Reflection - Metacognition}

Cultural metacognition, like mindfulness, refers to the ability to reflect on personal thought processes and behaviours (Thomas 2006). Crosscultural management studies increasingly utilises the concept of 'cultural intelligence', which is defined as 'the ability to generate appropriate behavior in an unfamiliar cultural setting'; cultural intelligence doesn't only serve to promote adaptation or assimilation, but also shapes 'the cross-cultural interaction context' (Thomas 2006: 80). However, in our study we view cultural intelligence not as something an individual has, but rather we apply the concept to a process of (intercultural) interaction (Plum et al. 2008) in which a number of contextual issues influence the outcome of the situation (Clausen 2007, Clausen and Worm 2010). The elements of cultural intelligence include knowledge, emotion and behaviour (Early and Ang 2003). In other words, individuals apply the three elements of cultural intelligence, mind, heart and action during their intercultural encounters (Plum et al. 2008). Mindfulness refers to an understanding of one's own cognitive behaviour and is therefore a linking process between knowledge and action. Mindfulness is a state of awareness between one's internal state and external stimuli. A person can also be mindful of thoughts, motives and emotions. Mindfulness is 'a specific meta-cognitive strategy that regulates cognition' (Thomas 2006: 86).

The concept of mindfulness can help to explain how behaviour is adjusted in a cross-cultural context, as well as how frame switching can be moderated. Ideally, if an individual is able to exert meta-cognitive reflection at all times, he or she will always be able to regulate thought and behaviour, and the notion that frame switching is an automatic response will be eliminated. It is unlikely that an individual would be able to remain in control of his or her thoughts, feelings and behaviour at all times, but we will nonetheless argue that the ability to apply metacognition is the primary value of bicultural competence. Understanding the meta-cognitive process of a bicultural individual who navigates culturally complex situations will teach us more about the connections being made between familiar and unfamiliar knowledge structures and may help the individual to successfully exert bicultural resourcefulness. The theories of frame switching and metacognition enable the explanatory framework presented in the matrix model shown in Figure 1, opposite. 


\section{Bicultural Resource Matrix}

The explanatory theoretical framework presented above allows for four categorizations, as displayed in this matrix.

Figure 1: Model of bicultural resourcefulness in context.

Reflection

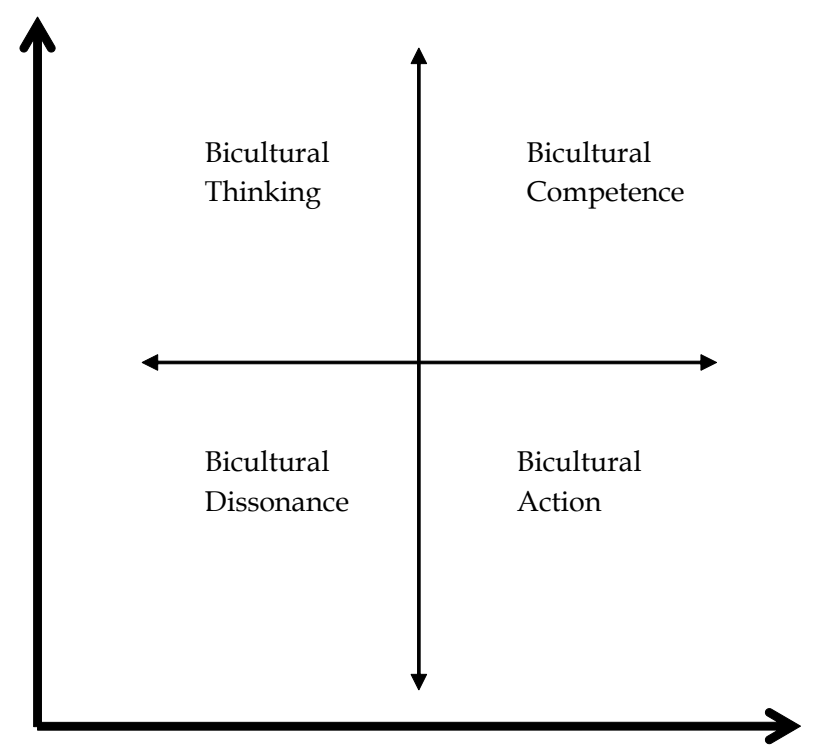

This model of bicultural resourcefulness illustrates the interplay between thought (reflection) on the vertical axis and action (frame switching) on the horizontal axis. The axes can be considered continuums on which an individual finds themselves in a given situation; it also shows how they might behave resourcefully in such a situation. In short, the model represents how a person acts (frame switches) and thinks (reflects) in a specific situation, as opposed to how the individual 'always' is. The individual thereby shifts in and out of the various squares, depending on how they relate to the specific situation. It is possible to move in either direction on the axes not only as a part of individual human development, but also from situation to situation. The horizontal axis represents the level of reflection an individual comfortably exerts from low to high. The vertical axis reflects how effortlessly a bicultural switches in and out of their cultural frames from low to high. A number of factors are likely to influence this, as exemplified in the following. The flow of explanation of the matrix is from the lower left hand quadrant: bicul- 
tural dissonance and the lower right-hand quadrant: bicultural action, to the upper left quadrant: bicultural reflection and to the upper right quadrant: bicultural resourcefulness.

\section{Bicultural Dissonance}

When operating from the lower left-hand quadrant, the individual experiences dissonance in relation to how they relate to their culture(s) in the situation at hand. Dissonance can occur, for instance, in a situation that causes psychological stress (Molinsky 2007) or where conflict between the cultures is experienced, as shown in the construct of bicultural identity integration (Benet-Martinez and Haritatos 2005). In such cases, the individual experiences difficulty in negotiating their culture(s) which, in the given context, generates a sense of either/or; the bicultural is prompted to make a distinct choice. Operating with low frame switching and low reflection is a situation where the bicultural may act from a single cultural perspective as they are not able to create consistency between cultural values and the burden of creating psychological consistency between value and action is too great. People hold different views (cognitions) about the world. When attitudes and values clash, the discrepancy results in a state of tension or sense of 'cognitive dissonance' (Festinger 1957) because there is a discrepancy between self-concept and cognition about behaviour. As the experience of dissonance is unpleasant, people are motivated to reduce this sensation through inward explanation or outward action towards agreement (consonance). A psychological toll is often (but not always) connected to the learning of biculturals (Hong 2010).

\section{Bicultural Acting}

When an individual operates within the lower right-hand quadrant, they perform frame switching (drawing upon knowledge and experience from two or more cultures). We argue that when operating with a high level of frame switching but with a low level of reflection (i.e. performing frame switches without metacognition), the complexity in the accessible knowledge structures are triggered and activated but without awareness. As mentioned above, this switch can also be caused by an experienced discomfort in a prior, similar situation, or when it is difficult to find harmony between the cultures. Operating with high frame switching but low reflection can be described as a situation where the individual switches frames automatically, based on immediate subtracted cues about how to behave in the setting (Hong et al. 2000). 


\section{Bicultural Thinking}

An individual operating within the upper left-hand quadrant performs few, if any, frame switches. This may be because they have not yet had the requisite experiences to be able to perform the switch, or because the bicultural is not used to relating to more than one of their cultures (e.g. it may have been many years since they were in touch with the second culture, or they prefer not to relate to the second culture based on previous experience). In this case, reflection on the given situation enables the individual to consciously draw on their knowledge structures in two cultures to create new ways of approaching a situation. However, for various reasons, they don't frame switch, but act primarily within the knowledge structure of a single culture.

\section{The Bicultural Competence}

The value of functioning within the upper right-hand square is that the bicultural individual can combine their high level of frame switching with a high level of reflection. This facilitates a situation where the individual is drawing on cultural knowledge as well as an awareness of how they respond to the situation. This means that they can tailor responses to a situation purposefully with an intended outcome. At the same time, combining metacognition and frame switching provides the bicultural individual with a cognitively complex way of thinking that allows them to consider the situation from a more intricate viewpoint, based on informed and deliberate choices.

\section{The Design of the Study}

This study comprises findings from two collaborative research projects: one conducted in an educational setting and one in corporations in East Asian countries.

The education study investigated the nature of biculturalism to understand how it was conceptualised by a group of students and to discover whether they found biculturalism to be a useful resource (Keita 2010). The interviews were conducted in March and April 2010 in the Asian Studies programme at Copenhagen Business School in an Intercultural Communication and Organizations class. The interviewees were a group of 10 students, all of whom self-identified as biculturals. Five of the 10 students were biological biculturals, i.e. they grew up with parents from two different cultures, two students were children of immigrant parents, and three students had acquired bicultural competences via long-term 
stays in two or more foreign cultures. The interviewees represented a wide variety of biculturals, which contributed to the scope of understanding provided by the study.

The corporate study investigated cultural collaboration and competence in the subsidiaries of two Danish multinationals in Japan in October 2009 and China in October 2010. The fact that one of the multinational corporations had recently hired a bicultural Danish/Chinese general manager for its Chinese operations provided further evidence that biculturalism is viewed as a resource in corporations. Expatriates and locals were interviewed as part of the project on cultural intelligence as a strategic resource in multicultural teams. ${ }^{3}$ A number of expatriate managers were identified as bicultural (either by birth or through education/experience). They were fluent in two languages: Danish and Chinese or Japanese. Four of their accounts were selected as 'exemplary cases' to demonstrate the four quadrants in the bicultural competence model (see Figure 1, above).

Both studies were explorative and used grounded theory (Glaser and Strauss 1967; Holton 2010), which enabled the empirical findings to be instrumental to theoretical understanding. One major finding was that there was a strong connection between cultural identity i.e. the sense of self in relation to cultural exposure (Jameson 2007), perception of biculturalism, i.e. primarily understood as the ability to switch cultural frames, to a large extent including language (Brannen and Thomas 2010, Ringberg et al. 2010), and bicultural resources (Hong 2010). This construct is similar to the triangulation between knowledge, emotion and action/behaviour in work on cultural intelligence (see Plum et al. 2008 and section 2, above).

Both studies explored the subjects' relationship with biculturalism, perceived strengths and weaknesses, ability to turn biculturalism into a resource and thoughts about being bicultural. In both studies, the semistructured interviews lasted, on average, one hour (Kvale 1996)

The questions included:

- What does it mean to you to be bicultural?

- Are there particular skills associated with being bicultural?

- Can you give examples of positive/negative experiences of being bicultural?

- Describe how you approach/what your role is in a crisis situation?

- To what extent have you capitalised on your biculturalism in your career? 
The educational study served as a preliminary to the corporate study. The names in the accounts are fictional to maintain the anonymity of the interviewees.

\section{Study One: Education}

The interviews with students were based on the hypothesis that these individuals would provide knowledge about their perceptions of biculturalism prior to gaining experience through organisational exposure (corporate work). Surprisingly (and contrary to findings in the corporate interviews) few students felt that biculturalism was a resource in social interaction. The study yielded four major observations as follows:

Figure 2. Study 1: Education. Showing the background of students their awareness of biculturalism as a resource. The 'switch over' and the 'stranger' are the respondents own words.

\begin{tabular}{|l|l|l|l|l|}
\hline STUDY 1 & EDUCATION & Sophie \\
\hline Students & Joanna & Fanny & Ted & $\begin{array}{l}\text { Philippine/ } \\
\text { Danish }\end{array}$ \\
\hline $\begin{array}{l}\text { Back- } \\
\text { ground } \\
\text { Expatriate child } \\
\text { in Norway and } \\
\text { Malaysia }\end{array}$ & $\begin{array}{l}\text { South Afri- } \\
\text { can/ German }\end{array}$ & $\begin{array}{l}\text { Taiwanese/ } \\
\text { Swedish }\end{array}$ & $\begin{array}{l}\text { Empathy and } \\
\text { reflexivity } \\
\text { 'stranger' in } \\
\text { two cultures }\end{array}$ \\
\hline $\begin{array}{l}\text { Exempli- } \\
\text { fies }\end{array}$ & Bridge building & 'Switch over' & $\begin{array}{l}\text { Bilingual/cul- } \\
\text { tural fluency }\end{array}$ & \multicolumn{3}{|l}{} \\
\hline General & NO AWARENESS OF BICULTURALISM AS A RESOURCE \\
\hline
\end{tabular}

\section{Bridge Building}

When asked directly to describe a situation where being a bicultural had proven to be a resource, the students' immediate response was that the notion was unthinkable. The interviewees were not intuitively aware of a resourcefulness originating in their biculturalism. However, some students with expatriate backgrounds came to the conclusion that they were able to contribute in particular situations on the basis of their bridge building abilities (Brannen 2009), but rarely in conscious action. For instance, Joanna (age 24), who lived with her parents as an expatriate in Norway and Malaysia during most of her childhood and youth, explained how she would mediate communication between her Norwegian and Danish classmates, particularly when the Danes did not understand certain Norwegian words: 'When she [the Norwegian classmate] spoke I could see on my Danish friends' faces that they weren't 
getting it, now, automatically, I wouldn't think about it, I would just automatically translate' (Interview, Joanna, 13 March 2010).

\section{'Switch over'}

The students commonly noted that the quality that set them apart from monoculturals was their 'ability to switch over' (Interview, Fanny, 8 April 2010). Fanny explained how she sensed her peers' bafflement when she performed actions that belonged specifically in her South African cultural context while being in her German context. For instance, her family's table manners drew attention from German friends who came home with her for dinner when her family customs had not been explained in advance. This self-awareness is interesting in light of the first finding: that the bicultural students did not perceive themselves as having any special resources because of their biculturalism. It appears that the (automatic, non-reflexive) frame switch was sometimes experienced as an obstacle by the interviewees, i.e. biculturals experience that outsiders or strangers perceive them as 'diffuse individuals' when they change behaviour without explaining why.

\section{Cultural Fluency}

It also became evident that an individual's bicultural origins, i.e. being the child of intercultural marriage or of immigrants, did not generate a strong awareness of bicultural resourcefulness. As expressed in the words of Ted, a Taiwanese-Swedish 21 year old born and raised in Sweden:

Well, I feel that I am mostly Swedish but I have some culture from my mother's side. But I understand it a bit more easily when I am in situations involving Chinese and Taiwanese people and I can understand what they say and talk about and what they write about. Otherwise I don't really use, or have such big use for the culture from my mother's side. (Interview, Ted, 9 March 2010)

Ted's statement expresses how biculturalism is conceived as a static condition that somehow provides the individual with a knowledge framework to draw upon, e.g. like knowing maths or being able to drive. This suggests that bicultural awareness is rooted in experience. Ted, for instance, had only visited his mother's home country once. Although she had taught him Taiwanese traditions and how to speak and read Chinese, Ted did not reflect on his biculturalism as something explicitly resourceful. 


\section{Empathy and Reflexivity: A Stranger in Two Cultures}

Sophie has a Filipino mother and a Danish father, i.e. she is biologically bicultural and has spent numerous holidays in the Philippines. She described how she experiences her mother's culture while primarily growing up in her father's in terms of being perceived as a stranger in both cultures (cf. Canetti 1996). She demonstrated knowledge of what it is like to visit a new culture, while at the same time sensing that she ought to feel at home in this culture. This sense of obligation was based on an emotional attachment to her maternal heritage. She shared a story about how she invited a Korean exchange student over to her house to bake. Her motivation was twofold: she wanted to satisfy her personal curiosity about Korean culture and she also wanted to accommodate the exchange student, whom she imagined, probably felt like 'a stranger' far from home. Her account illustrates how she acted consciously, on the basis of her past experiences. She reflected on the emotions of others, recalling familiar feelings of insecurity, thereby displaying high levels of reflectiveness (metacognition) (Interview, Sophie, 23 March 2010).

\section{Education Interviews Summarised}

In the educational study we inquired into the awareness of what it means and what particular skills are associated with being bicultural. There was a prevailing sense that the students did not think of their biculturalism as a resource. Only a few of the students were able to conceptualise their experiences in terms of bicultural resources. Biculturalism was conceived as an ability to switch over or build bridges, identified in some but not all cases with bilingualism (cf. Brannen and Thomas 2010, Ringberg et al. 2010). It was also perceived as an action: performing a cultural frame switch, from one set of cultural rules to another (cf. Molinsky 2007, Briley et al. 2005). The extent to which the students experienced their biculturalism as a resource was not determined primarily by the origin of their biculturalism (biological or through experience), but rather by how they related to their biculturalism and their previous experiences and perceptions of who they were in relation to their cultural identity, i.e. their level of reflectiveness. Some were able to reflect on their biculturalism and bicultural qualities, such as cultural frame switching and bilingualism, but these were not perceived as singular abilities identified as resources. When asked to what extent they had capitalised on their biculturalism in their career, they were not aware that these abili- 
ties would be viewed as resources. In relation to the model, the four students voiced a range of personal coping strategies: from dissonance to action and from reflection to initiative to take action using bilingual competence. However they did not consider these skills to be a special bicultural resource.

Importantly, the categories in the model exemplify modes as experienced in situational social encounters rather than a progressive development from dissonance to competence. The model can also be applied in to the corporate situation.

\section{Study Two: Corporate}

The following interviews were conducted with three biculturals in two Danish multinational corporations (MNC) in China and one bicultural in a MNC in Japan ${ }^{4}$. The data was also applied to the bicultural resource model used in the education study.

\section{Cognitive Dissonance}

Ulrick has a Master's degree in Chinese language and culture. We class him as Danish/Chinese by education. He has native knowledge of Chinese language and culture and spent a year at a Chinese university to refine his language skills. He initially ventured to China to seek out opportunities; he was hired by a company in China to take care of logistics, including IT projects and planning of production processes and managing Chinese workers. He was hired locally, which makes his contract less lucrative and less connected with headquarters than those held by other expatriates. Nevertheless, the job has provided an opportunity to gain work experience in China. In his view, the main resources he brings to the team are his Chinese language ability, his thirst for knowledge and his ability to learn things quickly. He finds the Chinese to be extremely effective in their work. Their willingness is impressive. What he finds frustrating and tiring is: a) the communication between headquarters located in Denmark and his unit in China is poor and urgent matters are not always treated accordingly; and b) logistics and production are not always aligned. As a middle manager he feels stuck between different agendas, priorities and management styles.

The company policy is to try to make workers feel at home and part of the corporation. This is implemented through 'conversation as friends', with workers at all levels. He finds this practice to be awkward due to his observation of its incongruence with Chinese management styles. 
In factories in the neighbouring area the management style is strict and impersonal. The Danish corporate idea is to treat people well, (this includes maintaining high safety standards, which he agrees with), and to treat employees as part of the family. His in-between position and learned knowledge about Chinese practices make him 'incapable of chitchatting about people's personal lives' (Interview, Ulrick, October 2010). He makes an effort because he is asked to, but he finds it difficult. We position him in the category of 'bicultural dissonance' as his knowledge and reflection about values in both cultures become a double bind - a catch 22 - which he, in this situation, is not able to resolve through either external action or internal change of values (cf. Festinger 1957). He is exhausting himself emotionally as he cannot maintain equilibrium and peace of mind regarding this matter.

\section{Bicultural Action}

Dan is a production manager in charge of a new production line. He is a trainer and also involved with lean processes. He belongs to a new generation of young managers within the company who collaborate across borders on different projects. He has worked on a lean production project with international colleagues from England, Germany, Denmark, Indonesia, India, Thailand and now China. He is fluent in Chinese and when you observe him in action on the assembly lines in the factory, he switches between English, Danish and Chinese effortlessly. This fluency was noted by people in the lean education team and the human resources team visiting from headquarters. They said that they would naturally seek him out as a partner in projects due to his direct access to the Chinese workers through his language abilities. His rapid promotion through management and the company's trust in his ability as a mediator between management and Chinese workers on the floor are very apparent. He did not, however, reflect on his bicultural abilities in the interview. We place him in the category of 'bicultural action' which implies tacit knowledge and agile action in both cultures, but without expressing elaborate reflections about learning.

\section{Bicultural Reflection}

Lars is Danish. He is fluent in Japanese, learned as a student in the Asian Studies Programme discussed above, where he obtained a Master's in business administration. He previously worked for an international company in Japan and was 'headhunted' to work in Tokyo for a Danish MNC specialising in industrial goods. He belongs to several networks 
within the organisation's sites in Japan and across the region. At the time of the interview, he was working closely with people who were setting up a business service centre in China. He is close to his line function managers in Denmark and has become both a formal and informal node of communication. A number of people in the Japanese organisation do not speak English and he often mediates and verifies information before and after meetings. A number of Japanese employees use him to understand the agenda for meetings. In meetings, he has also taken on the role as the spokesperson for people who do not speak out. The executive management, who were at that time dealing with restructuring in Japan (and who do not speak Japanese), used him to understand what was happening within the organisation.

The agenda from headquarters aimed to standardise products and services for efficiency purposes, while the Japanese enjoyed close connections with customers and wished to cater for individual solutions. The dilemma is that these complex views are polarised. Lars' linguistic competence positions him as a mediator in conflicts. Meanwhile, his personal views on work-life balance have become problematic. He maintains his right to the Danish legal standards of a 40-hour working week with 6 weeks of holiday a year. These standards have not been installed in the Japanese organisation. His insistence on maintaining his Danish rights can lead to heated discussions about the contrast between expatriate Danish and local working conditions. His cultural and language abilities are an asset in a number of many ways but to some extent his position isn't easy in relation to orders of command and power relations. We place him in the 'bicultural reflection' category due to his vast knowledge but less advanced ability to act in resourceful ways to the advantage of himself or the company.

\section{Bicultural Competence}

Zen is a bicultural from Denmark and South Africa. He was hired by the company straight from the Danish Technical University and holds a management position in the production section of one of the factories in China. He is also engaged in the implementation of a lean production system inspired by the Japanese Toyota system. The production plant aims to optimise efficiency and find new ways of limiting waste; this requires in depth study of people and systems.

He has previous experience of setting up production systems in Indonesia. His working motto is that 'I need my staff to work with their hearts'; he also notes that 'it is important that you do not generalize and 
that each person has to be treated differently' (Interview, Zen, October 2010). As such, he is careful to engage and reward workers in different ways. For example, he observes that most Chinese are keen on making money. They expect that each step up in their performance or each additional qualification will bring them more money in their paycheque; he attempts to comply with this expectation.

His main resources as a bicultural are: a) being open to difference, not narrow-minded or judgmental; b) his ability to handle culture shock; he sees how colleagues who are dispatched from headquarters seem to suffer in the new culture but he has not himself encountered these down periods; and c) his ability to let go and trust that people can handle their responsibilities. He does not feel that he has to be present to control the processes but leaves his people in the production line to do their job even when he is out of sight (this is in contrast to colleagues who continuously survey the process). He believes this inculcates a sense of responsibility over time, even if the process is challenging: 'You need to spend time, time and time again to explain procedures and production steps; it can be frustrating' (Interview). The culture at this factory is open and dynamic; communication between employees is valued. According to Zen, learning and acquiring new skills 'is all about exposure' (Interview). Brought up in South Africa and Denmark, he also has work experience in India. The exposure and lived experience creates openness to different national and professional cultures, as well as quick adaptation to new working procedures and management styles. He has learned to apply different management techniques in different contexts. Finally, he is quick to detect when things aren't working. This saves time. He is 'honest' and straightforward with his employees. His weak point is that he is easily irritated, but he is aware of this and is working to improve it. The main resource of a bicultural, in his view, is the ability to 'play the cords on different instruments' (Interview); he uses frame switching consciously. We place him in the 'bicultural competence' category. He displays a high level of reflection and high level of conscious (resourceful) action.

\section{Corporate Interviews Summarised}

The corporate examples demonstrated that biculturalism involved cultural frame switching. The level of reflection about frame switching varied in the four modes of biculturalism. The first example, the Danish/Chinese (by education) Ulrick, displayed knowledge of the practices of two cultures but felt uneasy as he had no sense of being at home in 
either setting. This is described as cultural dissonance. In certain situations, the knowledge of two cultures was actually a liability. Rather than leading to action through knowledge about appropriate behaviour in two settings, this led to confusion and in some instances remained unexploited and action was stifled. In short, conversion was not possible. Dan, the Danish/Chinese (by education) was able to translate his experiences into practice (cultural action) in different settings, but he was not able to verbalise his processes. Lars, the Danish/Japanese (by education) was aware and capable of explaining practices (cultural reflection), but he was not able to turn his knowledge into meaningful action. Zen, the South African/Dane (by birth and upbringing) displayed conscious reflectiveness. Further, his bicultural competence from both cultural exposure and experience was transferred to generic knowledge, which was a) applicable in China b) and made explicit (reflected upon) in the interview. He not only perceived himself as bicultural, he was also considered a resourceful bicultural by his colleagues and employers.

\section{Conclusion}

Our study provides insights into bicultural theories of frame switching (Hong 2010) and metacognitive reflection (Thomas 2008). These concepts served as our analytical framework and inspired a dynamic matrix model that presented four modes of bicultural resourcefulness in context: bicultural dissonance, bicultural reflection, bicultural action and bicultural competence.

The most important observation in the self-assessment of the bicultural students was that the majority were not aware of the resources they had acquired through their bicultural upbringing or education. However, the observations of bicultural employees in MNCs showed how these abilities become resources when brought into play at the individual, team or corporate level. While the students in the educational programme did not consider their bicultural background to be a merit, the managers in the corporations in China and Japan displayed awareness of their competences.

\section{Implications for Theory}

Our study has shown that in terms of bicultural resources, the major influencer was not the origin of biculturalism, i.e. whether biological or through experience, but rather how the individual related to their biculturalism and their previous experiences and how they perceived 
their own cultural identity (cf. Jameson 2007). The ability to reflect on thoughts and behaviour determined whether or not biculturalism was perceived and experienced as a resource. Thus, bicultural qualities, such as cultural frame switching and bilingualism, were not seen as singular abilities identified as resources.

Further, our data indicated that time is a defining factor in self-perception and awareness of cultural competence (LaFromboise et al. 1993). The interviewees in the corporations in Asia were comparatively older/ further into their professional lives than the students in the educational programme. Experience has significant role in cultural learning processes (Blasco et al 2012). The students did not have the organisational membership and professional contributions referred to in the accounts of their corporate counterparts. Experience resulted in greater awareness of bicultural competences and viewing these as resourceful. Testing their skills in practice enabled the corporate interviewees to acknowledge their bicultural contributions in light of what their peers were able to do in similar hands-on situations.

It also became evident that bicultural resourcefulness involves both culture-specific knowledge (Hong 2010) and culture-general adaptability of this knowledge (Thomas 2006, Thomas et al, 2008). Our study showed that the most resourceful biculturals were able to reflect elaborately, employing metacognitive skills (Thomas, 2008).

\section{Implications for Practice}

These observations lead us to conclude that more focus on bicultural competences in education systems may be fruitful in tapping into this valuable resource. The surrounding society in the present study is Danish and Denmark does not promote the benefits of a multicultural society. This may be a direct cause of the lack of awareness among the students in assessing their abilities.

Textbook information about a host culture is rarely sufficient to make the best possible transition from working in a familiar (family) setting to being thrust into unfamiliar living and working environments abroad. Study programmes designed to educate individuals to embrace global professionalism are important in terms of introducing students to literature from a wide range of cultural viewpoints, but greater emphasis on the value of biculturalism (multiculturalism) is needed. It may also be useful to involve current or former expatriates in preparing future expatriates for life beyond the classroom. Greater emphasis could also be placed on teaching the processes of intercultural interaction, i.e. training 
reflection (metacognitive) ability in the classroom.

In global corporations, awareness of the benefits of bicultural competences in collaboration and knowledge-sharing may lead to a situation where businesses ask that educational institutions find new ways of training global leaders (Nng 2010) and nurturing mixed-cultural sensibilities (Brannen 2009).

Reflecting once more on Sun Tzu, biculturals have a rare receptiveness and special sensitivity towards their neighbour's position (through scrutiny of self) and this may be their most valuable trait. Awareness of bicultural practices can be incorporated into best practice, thereby enabling productive collaboration across cultural borders.

Lisbeth Clausen is an Associate Professor at the Copenhagen Business School. Her research interests are corporate communication and cultural globalisation, with a focus on Japan. Her most recent book is titled Team dynamics and diversity. Japanese corporate experiences (2015). Email: lc.ikl@cbs.dk

Maria Hvass Keita is an Executive Consultant at the Children and Youth Foundation. Her research interests include African business development, the African narrative and the role of partnerships between civil society organisations, corporations and governments. Email: mariahvasskeita@gmail.com

\section{NOTES}

1 We would like to thank the anonymous reviewers for their excellent comments, and particularly for pointing out that we should focus more sharply on the fact that the biculturals in the education study did not view their biculturalism as a resource.

2 We choose to use the term 'bicultural', as multiculturalism is commonly used to describe the presence of people from different cultural backgrounds in a group, and may therefore be confused with cultural diversity within a single individual (Brannen and Thomas 2010). This choice of terminology is in line with the common usage within the field of studies of biculturalism (Brannen and Thomas 2010).

3 The interviews in the corporate study were conducted by Verner Worm and Lisbeth Clausen in China and Lisbeth Clausen in Japan, as part of the Cultural Intelligence as a Strategic Resource in Multicultural Teams project, funded by the Danish National Strategic Research Council (2008-2011). The participants were Lisbeth Clausen, Martine Cardel Gertsen, Michael Jacobsen, Liv Egholm Feldt, Anne Marie Søderberg, Verner Worm and Mette Zølner.

4 The interviews were conducted by Lisbeth Clausen in Japan and Verner Worm and Lisbeth Clausen in China as part of the Cultural Intelligence as a Strategic Resource in Multicultural Teams project. 


\section{REFERENCES}

Adler, Nancy J., and Gunderson, Allison. 2008. International Dimensions in Organizational Behavior. (5th Edition, 2002). Mason, Ohio: Thomson Learning.

Benet-Martínez, Verónica, and Haritatos, Jana. 2005. Bicultural Identity Integration (BII): Components and Psychological Antecedents. Journal of Personality, 73(4).

Blasco, Maribel. 2015. Making the Tacit Explicit: Rethinking Culturally Inclusive Pedagogy in International Student Academic Adaptation. Pedagogy, Culture and Society, 23(1): 85-106.

Blasco Maribel, Egholm-Feldt, Liv, and Jacobsen, Michael. 2012. If only Chameleons could fly too. International Journal of Cross-cultural Management August. 12(2): 229245.

Brannen, Mary Yoko, and Thomas, David C. 2010. Bicultural Individuals in Organizations: Implications and Opportunity. International Journal of Cross-cultural Management, 10(1): 5-16.

Brannen, Mary Yoko, Garcia Dominie, and Thomas, David C. 2009 Biculturals as natural bridges for intercultural communication and collaboration. 2nd International Workshop on Intercultural Collaboration. ICIC: 207-210.

Brannen, Mary Yoko. 2009. Culture in context. In Beyond Hofstede: Culture Frameworks for Global Marketing and Management. Nakata, C. (ed). New York: Palgrave Macmillan: 81-100.

Brannen, Mary Yoko. 2004. When Mickey loses face: Recontextualization, semantic fit, and the semiotics of foreignness. Academy of Management Review, 29(4): 593-616.

Briley, Donnel A., Morris, Michael W., and Simonson, Itamar. 2005. Cultural Chameleons: Biculturals, Conformity Motives, and Decisions Making. Journal of Consumer Psychology, 15(4):351-362.

Clausen, Lisbeth, and Worm, Verner. Corporate 2010. Cross-Cultural Collaboration the Contextual Challenges of Multi-cultural Teams in China and Japan. Proceedings of the 3rd ACM International Conference on Intercultural Collaboration ICIC, August 18-20, Copenhagen, Denmark. ACM Press: 239-242.

Clausen, Lisbeth. 2007. Corporate Communication Challenges. A 'negotiated' culture perspective. International Journal of Cross-cultural Management 7(3): 317-332.

Clausen, Lisbeth. 2015. Team Dynamics and Diversity. Japanese Corporate Experiences. Copenhagen: Copenhagen Business School Press.

Canetti, Elias. 1996. Masse og Magt. Bd. 1-2. Samlerens Bogklub (Politiskrevy): Denmark.

Earley, Cristopher P., and Ang, Soon. 2003. Cultural Intelligence: Individual Interactions across Cultures. Stanford: Stanford University Press.

Fitzsimmons, Stacey R., Miska, Christof, and Stahl, Günter K. 2011. Multicultural employees: Global business' untapped resource. Organizational Dynamics, 40(3): 199-206.

Gillespie, Kate, McBride, Brad J., and Riddle, Liesl. 2010. Globalization, Biculturalism and Cosmopolitanism: The Acculturation Status of Mexicans in Upper Management. International Journal of Cross-cultural Management, 10 (1): 37-53.

Furusawa, Masayuki, and Brewster, Chris. 2015. The bi-cultural option for global talent management: The Japanese/Brazilian Nikkeijin example. Journal of World Business. 50(1): 133-143.

Holton, Judith A. 2010. The Coding Process and Its Challenges. The Grounded Theory Review 9 (1), 21-40.

Hong, Hae-Jung. 2010. Bicultural Competence and its Impact on Team Effectiveness. International Journal of Cross-cultural Management, 10(1): 93-120.

Hong, Ying-yi, Morris, Michael W., Chiu, Chi-yue, and Benet-Martínez, Verónica. 2000. 
Multicultural Minds: A Dynamic Constructivist Approach. American Psychologist, 55 (7): 709-720.

Jameson, Daphne A. 2007. Reconceptualizing cultural identity and its role in intercultural business communication. Journal of Business Communication, 44(3): 199-235.

Keita, Maria Hvass. 2010. Bicultural Resources in a Global Business Context. Master's Dissertation. Copenhagen: Copenhagen Business School.

Kvale, Steinar 1996. An Introduction to Qualitative Research Interviewing. London: Sage.

Lakshman C. 2013. Biculturalism and attributional complexity: Cross-cultural leadership effectiveness Journal of International Business Studies, 44: 922-940.

Lynton, Nandani, and Thøgersen, Kirsten Høgh. 2006 How China transforms an executive's mind.Organizational Dynamics, 35(2): 10-181.

LaFromboise, Teresa D., Coleman, Hardin L.K., and Gerton, Jennifer. 1993. Psychological impact of biculturalism: Evidence and Theory. Psychological Bulletin, 114(3): 395-412.

McCall Jr., Morgan W., and Hollenbeck, George P. 2002. Developing Global Executives. The Lessons of International Experience. Harvard Business School Press.

Molinsky, Andrew. 2007. Cross-cultural Code-switching: The Psychological Challenges of Adapting Behavior in Foreign Cultural Interactions. Academy of Management Review, 32(2): 622-640.

Peltokorpi, Vesa, and Clausen, Lisbeth. 2011. Linguistic and Cultural Barriers to Intercultural Communication in Foreign Subsidiaries. Asian Business \& Management, 10(4): 509-528. 10.1057/abm.2011.20.

Plum, Elisabeth, Achen Benedikte, Dræby, Inger, and Jensen, Iben. 2008 Cultural Intelligence. The Art of Leading Cultural Complexity. London: Middlesex University Press.

Ringberg, Torsten V., Luna, David, Reihlen, Markus, and Peracchio, Laura A. 2010. Bicultural Bilinguals: The Effect of Cultural Frame Switching on Translation Equivalence. International Journal of Cross-cultural Management 10 (1): 77-92.

Rogers, Everett M., Hart, William B., and Miike, Yoshitaka. 2002. Edward T. Hall and the History of Intercultural Communication: The United States and Japan. Keio Communication Review. 22. 3-26.

Stacey, Ralph D. Strategic Management and Organisational Dynamics. The Challenge of Complexity (5th edition). London: Prentice Hall

Tadmor, Carmit T, and Tetlock, Philip E. 2006. Biculturalism: A Model of the Effects of Second-Culture Exposure on Acculturation and Integrative Complexity. Journal of Cross-cultural Psychology, 37: 173-190.

Thomas, David C. 2006, Domain and Development of Cultural Intelligence: The Importance of Mindfulness. Group \& Organization Management, Vol. 31, No. 1, pp. 78-99.

Thomas, David C., Elron, Efrat, Stahl Günther, Ekelund Bjørn Z., Ravlin Elizabeth C., Cerdin Jean-Luc, Poelmans Steven, Brislin Richard, Pekerti Andre, Aycan Zeynep, Maznevski Martha, Au Kevin, Lazarova Mila B. 2008. Cultural Intelligence: Domain and Assessment. International Journal of Cross-cultural Management, 8(2): 123-143.

Tzu, Sun. 2012. The Art of War. Translated by James Trapp. New York: Chartwell Books, Inc. 